\title{
Transgenerational effects of maternal sexual interactions in seed beetles
}

\author{
Susanne R. K. Zajitschek $\mathbb{1}^{1,2}$ - Damian K. Dowling ${ }^{2} \cdot$ Megan L. Head $^{3}$ - Eduardo Rodriguez-Exposito ${ }^{1}$. \\ Francisco Garcia-Gonzalez ${ }^{1,4}$
}

Received: 3 November 2017 / Revised: 14 March 2018 / Accepted: 23 April 2018 / Published online: 25 May 2018

(c) The Genetics Society 2018

\begin{abstract}
Mating often bears large costs to females, especially in species with high levels of sexual conflict over mating rates. Given the direct costs to females associated with multiple mating, which include reductions in lifespan and lifetime reproductive success, past research focused on identifying potential indirect benefits (through increases in offspring fitness) that females may accrue. Far less attention has, however, been devoted to understanding how costs of sexual interactions to females may extend across generations. Hence, little is known about the transgenerational implications of variation in mating rates, or the net consequences of maternal sexual activities across generations. Using the seed beetle, Callosobruchus maculatus, a model system for the study of sexual conflict, we investigate the effects of mating with multiple males versus a single male, and tease apart effects due to sexual harassment and those due to mating per se, over three generations. A multigenerational analysis indicated that females that were exposed to ongoing sexual harassment and who also were permitted to mate with multiple males showed no difference in net fitness compared to females that mated just once without ongoing harassment. Intriguingly, however, females that were continually harassed, but permitted to mate just once, suffered a severe decline in net fitness compared to females that were singly (not harassed) or multiply mated (harassed, but potentially gaining benefits via mating with multiple males). Overall, the enhanced fitness in multiply mated compared to harassed females may indicate that multiple mating confers transgenerational benefits. These benefits may counteract, but do not exceed (i.e., we found no difference between singly and multiply mated females), the large transgenerational costs of harassment. Our study highlights the importance of examining transgenerational effects from an inclusive (looking at both indirect benefits but also costs) perspective, and the need to investigate transgenerational effects across several generations if we are to fully understand the consequences of sexual interactions, sexual conflict evolution, and the interplay of sexual conflict and multi-generational costs and benefits.
\end{abstract}

Electronic supplementary material The online version of this article (https://doi.org/10.1038/s41437-018-0093-y) contains supplementary material, which is available to authorized users.

Susanne R. K. Zajitschek

susi.zajitschek@gmail.com

Estación Biológica de Doñana - CSIC, Seville 41092, Spain

2 School of Biological Sciences, Monash University, Clayton 3800 VIC, Australia

3 Research School of Biology, Australian National University, Canberra 0200 ACT, Australia

4 Centre for Evolutionary Biology, School of Biological Sciences, The University of Western Australia, Crawley 6009 WA, Australia

\section{Introduction}

Sexual interactions usually bear large costs on the participants. Often, investment in current reproduction trades off against future reproduction and lifespan (Reznick 1985; Williams 1966). While sexual interactions and mating are necessary to ensure fertilisation in sexually reproducing organisms, and hence are the cornerstone for the production of progeny, associated costs can be substantial. Specifically, females of many species incur large direct costs; elevated mating rates can substantially depress fecundity and longevity for females (Arnqvist and Nilsson 2000; Blanckenhorn et al. 2002; Crudgington and Siva-Jothy 2000; Gavrilets et al. 2001). This has been particularly well documented in the fruit fly Drosophila melanogaster, where seminal proteins that are transferred with the male ejaculate 
decrease female longevity (Chapman et al. 1995). However, even co-habitation and harassment without successful copulation have been shown to be detrimental for female fitness in this species (Partridge and Fowler 1990).

Mating at a higher frequency than is required to fertilise a complete set of ova can be a result of sexual conflict over mating rates, which is common in the animal kingdom because of strong selection on males to maximise their reproductive success (Arnqvist and Rowe 2005; Chapman et al. 2003; Parker 2006). High rates of female sexual interactions may also evolve adaptively if direct benefits, such as mating gifts or paternal care, are gained (Arnqvist and Nilsson 2000), or if females benefit indirectly (via genetic benefits) by producing fitter offspring as a result of elevated sexual interactions and matings with multiple males (Jennions and Petrie 2000; Kokko et al. 2003). In many species, there are no apparent direct benefits associated with mating with multiple males (Arnqvist and Kirkpatrick 2005; Jennions and Petrie 2000), and for this reason, the majority of research in this field has focussed on whether the direct costs associated with multiple mating can be compensated by the production of fitter offspring (Chapman et al. 2003; Holland and Rice 1998; Kokko et al. 2003).

Theory predicts that indirect genetic benefits are unlikely to outweigh the direct costs incurred by females (Cameron et al. 2003). Empirically this has been supported by a range of studies (see Arnqvist and Nilsson 2000), for example in the common lizard Lacerta vivipara (Le Galliard et al. 2008) and in the fruit fly D. melanogaster (Brommer et al. 2012; Orteiza et al. 2005; Stewart et al. 2008, 2005). Nonetheless, there are also studies in D. melanogaster acknowledging major fitness benefits of mating with multiple males due to genetic benefits (i.e., indirect benefits). For example, more fecund D. melanogaster daughters compensate for the direct costs of mating incurred by their mothers (Priest et al. 2008a, b). Mating multiple times with different males may allow females to mate with more attractive mates, generating genetic benefits. Some studies show that fitness benefits via attractive sons may indeed outweigh direct costs, such as in the house cricket Acheta domesticus (Head et al. 2005), and D. melanogaster (Rundle et al. 2007). Similarly, benefits in the form of increased offspring viability cancel out the direct costs (decrease in female longevity) of mating in the Australian field cricket, Teleogryllus oceanicus (Garcia-Gonzalez and Simmons 2010).

Recent studies showing that transgenerational costs may exacerbate the direct costs to females (Dowling et al. 2014; Gasparini et al. 2012), or invoke opposing effects across different generations (Brommer et al. 2012) add further insights into understanding the fitness consequences of sexual interactions.. These transgenerational effects (TGEs), which may be inherited non-genetically (e.g., including epigenetic mechanisms), include indirect genetic effects (IGEs), and encompass maternal effects, paternal effects and effects via interacting phenotypes (i.e., non-sire influences on offspring life history trajectories; see GarciaGonzalez and Dowling 2015; García-González and Simmons 2007). TGEs have been identified as important factors influencing the fitness of offspring across generations following sexual interactions. Recent studies have demonstrated transgenerational costs to females that are brought about by sexual interactions: the effects of heightened (in both intensity and frequency) sexual interactions and increased harassment lead not only to longevity costs in female Drosophila melanogaster themselves (direct costs), but also to longevity costs in their offspring, adding therefore a transgenerational cost (Dowling et al. 2014). Similarly, higher levels of male sexual harassment in female guppies (Poecilia reticulata), led to lower reproductive success for their sons and daughters (Gasparini et al. 2012). Moreover, a study in D. melanogaster reported that females that were exposed to mating at different rates, produced sons with increased fitness, but grandsons with decreased fitness (Brommer et al. 2012). Opposing effects in descendants of different sexes may be due to negative genetic correlations for fitness between the sexes, or parents and offspring. Such negative genetic correlations have been reported in D. melanogaster (Brommer et al. 2012; Chippindale et al. 2001; Pischedda and Chippindale 2006), and also in other species such as the southern ground cricket Allonemobius socius (Fedorka and Mousseau 2004) and red deer (Cervus elaphus, Foerster et al. 2007). These studies highlight the importance of considering the sex-specific nature of cross-generational costs and benefits, because the benefits of mating with multiple males may disappear due to conflicting effects across generations or due to opposing effects within the sexes.

Here, we report effects of maternal mating history on female lifetime reproductive success (LRS) across three generations, and on offspring and grand-offspring longevity, in both sexes, in the seed beetle Callosobruchus maculatus. Specifically, after an initial baseline mating, which rendered females non-virgins, we exposed females to one of three maternal mating treatments. These were a treatment of no further male exposure (single mating), a treatment of harassment by multiple emasculated males incapable of insemination, and a treatment of multiple mating with multiple males capable of harassing females and successfully inseminating them. We investigated differences across treatments in offspring production in each generation separately, and also calculated the net consequences of each of the mating treatments by examining female offspring production across all three generations, to gain an understanding of the multigenerational economics 
of maternal sexual interactions. We discuss how exposure to sexual interactions may influence the evolution of mating systems, and the importance of these interactions and ensuing TGEs for population growth rates. Our study highlights the effects of non-genetic inheritance and the transgenerational consequences of sexual interactions on net fitness and population growth rates.

\section{Methods}

We used virgin male and female seed beetles (Callosobruchus maculatus) in our experiments. These beetles were sourced from an outbred population (South Indian stock population, SI, obtained from a replicate held at Uppsala University and prior to this kept by C. W. Fox at the University of Kentucky), which exhibits substantial phenotypic and genetic variance for a range of traits and behaviours (see for instance Fox et al. 2003; Berg and Maklakov 2012; Berger et al. 2014; Bilde et al. 2008). The stock population at Doñana Biological Station was established in 2013 using more than 450 founders and has been cultured since then in non-overlapping generations on organic mung beans (Vigna radiata) that are frozen prior to use. The stock population is kept across multiple containers, each of which typically generates over a thousand adults per generation. Around 50 non-virgin adults (25 males and 25 females) are randomly selected in each container each generation and allowed to reproduce in a new container with uninfested beans. The effective population size for each replicated population exceeds 75 individuals, as the 50 adults are nonvirgins collected from containers with approximately 1000 individuals and females mate multiply. The high rates of female multiple mating in these populations mean that our estimate of $\mathrm{Ne}$ is likely to be an underestimate. Offspring from the different containers are admixed and redistributed every few generations, and thus the stock population is maintained at large population sizes (in excess of 300 individuals). Beetles are kept in walk-in climate chambers (Fitoclima $10000 \mathrm{EHF}$, Aralab) at a constant $29^{\circ}$ $\mathrm{C}$ temperature with $40 \%$ humidity and a $12 \mathrm{~h} / 12 \mathrm{~h}$ light/dark cycle.

\section{Maternal mating treatment}

We individually paired 120 virgin females and males and allowed them to mate once (Day 0). Seven pairs were excluded, as they did not mate in the time allocated ( $30 \mathrm{~s})$. After mating, each female was transferred immediately into an empty $30 \mathrm{ml}$ container. On day 1, the F0 females were separated at random into three treatment groups: (1) single mating (monogamous treatment, $\mathrm{M}$ ) - kept as is, with no further interactions allowed, (2) harassment $(\mathrm{H})$-four males that had been incapacitated to mate were added to each female's container. Incapacitation was conducted on five day old males, under $\mathrm{CO}_{2}$ anaesthetisation. Relaxation due to anaesthesia led to the eversion of the male aedeagus, which was surgically shortened by approximately $1 / 3$ in length using microscissors, removing the spiny tip of the aedeagus. The efficacy of this procedure was confirmed in preliminary tests: males did not achieve successful copulations but continued to harass females and attempt mating. In the last treatment, (3) multiple mating (polyandrous treatment, P) — each female was placed with four same-age stock males (who were not emasculated but were briefly anesthetized, similarly to males used in the $\mathrm{H}$ treatment, prior to their use) that could both harass and successfully mate with females.

Females were kept in their respective treatments until day 4 and the containers were checked daily for dead males, which were replaced immediately. While being kept without beans can suppress both egg laying as well as remating rates in the study species (Eady et al. 2004), continuous exposure to males is expected to lead to highly elevated harassment and remating rates. For instance, Eady et al. (2004) found that even under conditions of suppressed oviposition between 20 and $60 \%$ of females readily remated during a relatively short ( $<45 \mathrm{~min}$ ) second mating opportunity, which was provided $24 \mathrm{~h}$ after an initial mating. Undoubtedly, harassment and remating rates in $\mathrm{H}$ and $\mathrm{P}$ females respectively, each of which were continuously housed with four additional males for several days, would had been much higher. On day 5, males were discarded and females were transferred into single containers filled with approximately 40-70 mung beans for egg laying. Females were placed in containers with 40-70 new (i.e., uninfested) beans $0 \mathrm{~h}$ (day 5), $24 \mathrm{~h}$ (day 6) and $72 \mathrm{~h}$ (day 8) after the end of the mating treatment. They were kept and checked daily for survival in the last container until death. We set up a total of $41 \mathrm{~F} 0$ females in the M, 39 in the $\mathrm{H}$, and 34 in the $\mathrm{P}$ treatment. Female $C$. maculatus lay one egg per bean when provided with sufficient resources (Messina 1991), and the provision described above ensured that there was no larval competition (i.e., no more than one egg per bean), as bean provision matched the patterns of egg laying: fecundity is highest during the first day, decreasing quickly during the following days (Credland and Wright 1989). On average $( \pm \mathrm{SE})$, the females in our experiment produced $27( \pm 0.66)$ adult offspring $(53 \%)$ within the first $24 \mathrm{~h}$ of oviposition, 14 $( \pm 0.51)$ adult offspring $(27 \%)$ in the subsequent $48 \mathrm{~h}$, and only $10( \pm 0.35 ; 20 \%)$ adult offspring in the remaining time of their lives. The sum of adult offspring from all containers constitutes our measure of LRS for each female, calculated for each generation separately.

After allowing 1 week of larval development, we collected 12 single inoculated beans from the first egg 
containers that had been provided ("day 5": eggs laid 0-24 h after end of mating treatment) and placed them individually in Eppendorf tubes with holes for airflow, where they were kept until virgin adult beetles emerged. Of these, four males and four females randomly selected from each clutch were used as focal F1 individuals. The remaining beans from the first egg container and the remaining containers were kept until all offspring had hatched, and were frozen for later counting.

\section{F1: First offspring generation-sons and daughters}

Two days post emergence into adulthood, virgin daughters (up to four from each treated female) $\left(N_{\text {daughters }}=405\right)$ were each paired with same-age single virgin males derived from a standardized heterozygous line (cross between two nearisogenic lines that had been generated after following a brother-sister mating protocol for 33 generations). We utilized tester individuals with a standardized genetic background to minimize variance in reproductive success that would be attributable to genetic variance among the tester males. After $24 \mathrm{~h}, \mathrm{~F} 1$ females were provided clean beans (as described above for F0: 0, 24 and $72 \mathrm{~h}$ after separation from mate) for egg laying. We acknowledge that F1 and F2 females were younger at time of first bean provisioning, which may contribute to differences in offspring production between the generations. However, as we were especially interested in the variation in LRS across treatments within and across generations, rather than in the within-treatment changes over generations, this is not considered a problem. Females were monitored for lifespan daily. Grand-offspring were sourced from the first egg laying $(0 \mathrm{~h})$ container as before, but eight instead of 12 inoculated beans were isolated from each female this time. Due to equipment failure beyond our control, approximately $50 \%$ of containers in the second instalment (24-72 h since start of egg laying) for our assessment of LRS in this generation did not contain viable offspring. As we could not be certain that the containers in which offspring had emerged were unaffected (overall, unusually low numbers were observed), we excluded all containers from this instalment for the calculation of LRS in F1. We hence used only numbers for adult offspring from eggs that that were laid at $0-24 \mathrm{~h}$ and between $72 \mathrm{~h}$ until death for F1 LRS.

Up to four virgin sons per female were kept in individual Eppendorf tubes and monitored for lifespan, and survival checked once per day $\left(N_{\text {sons }}=393\right)$.

\section{F2: Second offspring generation-grandsons and granddaughters}

We mated two females from each daughter in the same manner as described for the previous generation
$\left(N_{\text {granddaughters }}\right.$ that successfully produced offspring $\left.=675\right)$. Emerging F3 offspring were frozen and counted. Lifespan was monitored as before by checking survival once per day in these F2 females ( $N=647$ instead of 675 , due to some females escaping at late-age) and in two additional virgin male offspring per family $\left(N_{\text {grandsons }}=679\right)$.

\section{Economics across three generations}

To calculate the across-generation female productivity for each treatment, in addition to comparisons of LRS in each of the generations separately, we approximated an index of LRS, based on average offspring numbers across individuals and their contribution to the next respective generation (for a hypothetical calculation example please refer to Table S1).

We counted total offspring numbers for LRS without distinguishing between the sexes, but assumed that offspring were produced in equal sex ratios (Reece et al. 2005). We only used $50 \%$ of the counted LRS numbers from each female in F0 and F1 for our calculation, due to the fact that we here only assayed female reproductive success. For each F0 female that successfully produced descendants through to $\mathrm{F} 3$, the index was calculated as:

$$
1 / 2(\mathrm{~F} 0 \mathrm{LRS}) * 1 / 2(\mathrm{~F} 1 \text { average LRS }) * \mathrm{~F} 2 \text { average LRS }
$$

\section{Statistical analyses}

All analyses were carried out in $\mathrm{R}$ (version 3.4.0, $\mathrm{R}$ Development Core Team 2012). Mixed model analyses on LRS and on lifespan were conducted using lme4 (Bates et al. 2015) and $p$-values extracted using lmerTest, (Kuznetsova et al. 2013. See http://cran.r-project.org/web/packa ges/lmerTest.), using mating treatment as a fixed factor. In analyses of F1 data, F0 female ID was added as a random variable. In analyses of F2 data, F1 ID nested within F0 ID was included as a random variable. Normality of residuals was visually confirmed. To run survival analyses and compare survival probabilities across the treatments, we used mixed Cox proportional hazard models using the R package coxme (Therneau 2015. See http://cran. r-project.org/web/packages/coxme.), with female IDs included as a random effect as detailed above. To further investigate potential trade-offs between survival and reproduction, LRS of the respective generation was added as a covariate into the model (see supplemental Table S2). We used Tukey multiple comparisons of means (TukeyHSD) to investigate differences between treatments in the LRS assays, and the glht function in package multcomp (Version 1.4-7, https://cran.r-project.org/web/packa ges/multcomp, Hothorn et al. 2008) for post hoc tests on lifespan and survival. Visual displays of the results (barplots) are based on means. Additional analyses investigating 

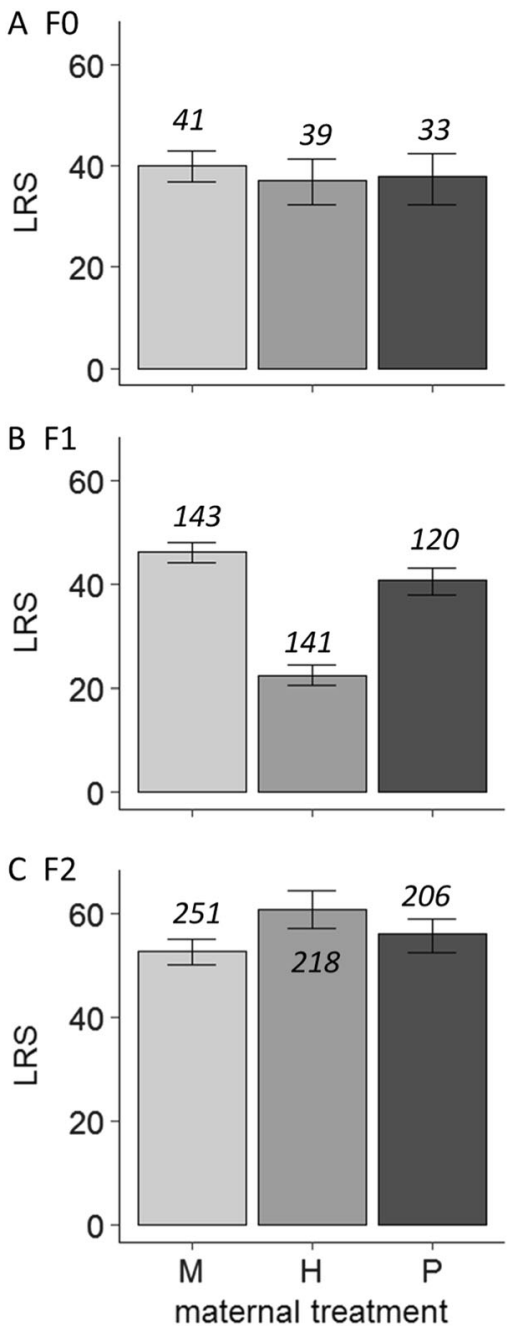

Fig. 1 Lifetime reproductive success in females at the F0, F1 and F2 generation respectively. Light grey: single mating in maternal generation (Mono, M), grey: single mating + harassment $(\mathrm{H})$, dark grey: multiple mating with multiple males (Poly, P). a maternal generation, b daughters, $\mathbf{c}$ granddaughters

mother-offspring correlations in reproductive success (Table S3) and lifespan are presented in the supplemental material (Table S4).

\section{Results}

\section{The maternal generation (F0)}

We found no effect of the mating treatment on female LRS $\left(F_{2,111}=0.625, p=0.5372\right.$, Fig. 1a). Furthermore, we detected no effects of mating treatment on lifespan $\left(F_{2,111}=\right.$ $0.592, p=0.555$, see also Table S2 for no evidence for lifespan-LRS trade-offs) or survival probability $\left(\chi^{2}=0.838\right.$, $\mathrm{df}=2, p=0.658)$. Furthermore, we find little evidence for cross-generation correlations of LRS (Table S3).

\section{Offspring (F1 and F2)}

\section{Lifetime reproductive success (LRS)}

\section{F1: Daughters}

The maternal mating treatment conferred strong effects on the LRS of females in the F1 generation $\left(F_{2,95}=101.53, p\right.$ $<0.0001)$. Daughters from singly mated F0 females produced the largest number of offspring (mean \pm SE, $46.2 \pm$ 1.01 ), followed by daughters of multiply mated F0 females (40.8 \pm 1.32$)$, and finally daughters of harassed F0 females produced the lowest number of offspring $(22.4 \pm 0.98$; all treatments significantly different from each other, Tukey's HSD test: M-H: $p<0.0001, \mathrm{M}-\mathrm{P}: p=0.0035, \mathrm{H}-\mathrm{P}: p<$ 0.0001 , see Fig. 1b).

\section{F2: Granddaughters}

Grand-maternal mating treatment also affected the LRS of the granddaughters $\left(F_{2,87}=6.220, p<0.003\right)$, but the pattern was reversed compared to the previous generation. Granddaughters from singly mated F0 females exhibited significantly lower levels of reproductive output (52.7 \pm 1.22) than granddaughters from harassed $(60.9 \pm 1.79)$, but not multiply mated $(55.9 \pm 1.65)$ F0 females (Tukey's HSD test: $\mathrm{M}-\mathrm{H}=-8.171, p=0.0004 ; \mathrm{M}-\mathrm{P}=3.19, p=0.3077$; $\mathrm{H}-\mathrm{P}=-4.981, p=0.0693$, see Fig. 1c). Overall, F2 females appear to show a classical offspring number/lifespan trade-off (Table S2), in contrast to females in the other generations.

\section{Lifespan}

\section{F1: Sons and daughters}

The mean lifespan $\left(F_{2,104}=4.001, p=0.0212\right)$ and survival probabilities $\left(\chi^{2}=44.79, \mathrm{df}=2, p<0.0001\right)$ of $\mathrm{F} 1$ daughters differed significantly according to the maternal mating treatment. Specifically, singly mated (M) F0 mothers produced shorter-lived daughters than harassed $(\mathrm{H})$ and multiply mated $(\mathrm{P})$ mothers (see Fig. 2a, c). In sons, neither lifespan $\left(F_{2,101}=1.80, p=0.2112\right.$, Fig. $\left.2 \mathrm{~b}\right)$ nor survival $\left(\chi^{2}\right.$ $=3.61, \mathrm{df}=2, p=0.165$, Fig. $2 \mathrm{~d}$ ) differed with maternal mating treatment. We did not detect any significant mother-offspring correlations in lifespan (see Table S4A).

\section{F2: Granddaughters and grandsons}

Granddaughters from all three maternal mating treatments differed significantly from each other, both in average lifespan $\left(F_{2,71}=16.352, \quad p<0.0001\right.$, Fig. 3a) and in survival probability $\left(\chi^{2}=34.17, \mathrm{df}=2,<0.0001\right.$, Fig. $\left.3 \mathrm{c}\right)$. 
Fig. 2 Average lifespan and survival curves for male (virgin) and female (housed with mates for $24 \mathrm{~h}$ ) offspring (F1).

Maternal treatment: Light grey: single mating (Mono, M), grey: single mating + harassment $(\mathrm{H})$, dark grey: multiple mating with multiple males, Poly, P). a daughters average lifespan, b sons average lifespan, survival curves for daughters (c) and sons (d)

\section{A Daughters Lifespan}
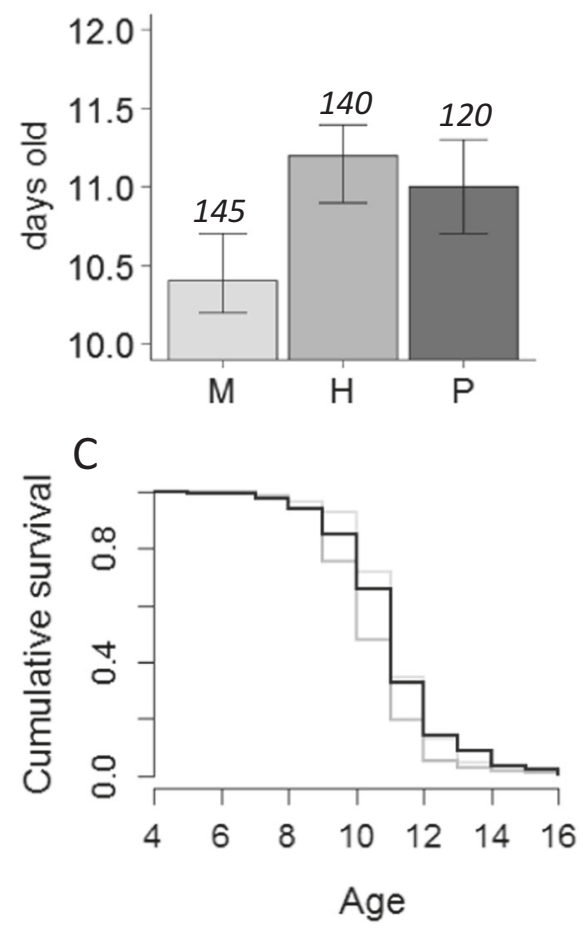

B Sons Lifespan
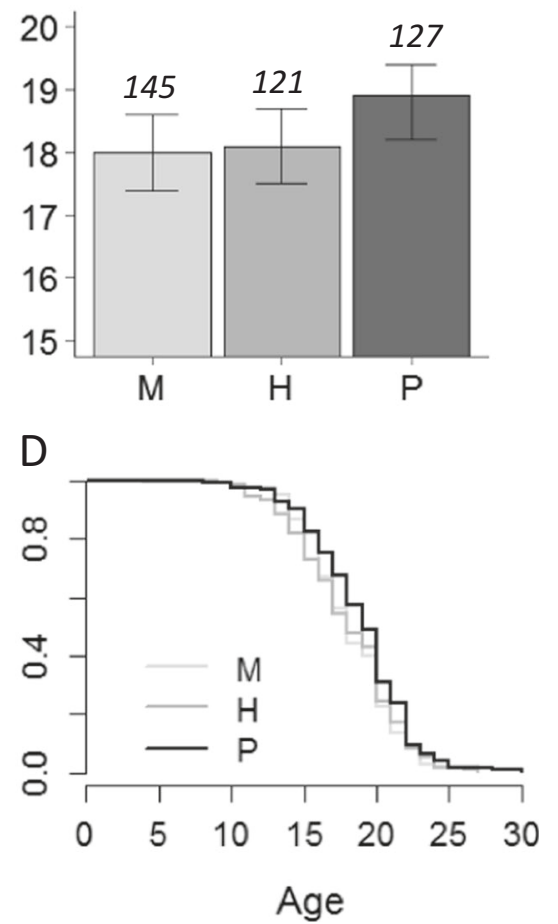

Specifically, descendants from the harassment treatment $(\mathrm{H})$ lived longest, $\mathrm{M}$ granddaughters were intermediate in lifespan (6\% shorter lifespan than $\mathrm{H})$, and $\mathrm{P}$ granddaughters lived shortest (12\% shorter lifespan than H; Fig. 3a, c; Tukey's HSD test: M-H: $z=-3.333, p=0.0026$; M-P: $z$ $=-2.952, p<0.009$; H-P: $z=-5.801, p<0.001)$. Interestingly, granddaughter's lifespan was significantly correlated with their grandmothers' (F0) but not their mothers' (F1) lifespan (see Table S4B).

The effect was similar for grandsons, with $\mathrm{H}$ descendants living the longest (14\% longer lifespan compared to $\mathrm{M}$, $12 \%$ longer than P descendants; $F_{2,95}=25.984, p<0.0001$; Tukey's HSD test: M-H: $z=-6.881, p<0.0001 ; \mathrm{M}-\mathrm{P}: z$ $=1.278, p=0.408$; H-P: $z=-5.324, p<0.0001$, Fig. 3b) and having the highest survival probability $\left(\chi^{2}=108.86, \mathrm{df}\right.$ $=2,<0.0001$, Tukey's HSD test: $\mathrm{M}-\mathrm{H}: \quad z=-6.980$, $p<0.0001$; M-P: $z=1.316, p=0.386$; P-H: $z=-5.374$, $p<0.0001$, Fig. 3d).

\section{Economics}

We find that maternal mating treatment had a highly significant effect on net fitness across the three generations examined $\left(F_{2,106}=6.82, p=0.0016\right.$, Fig. 4), with $\mathrm{H}$ females generating less than two thirds of descendants compared to the other treatments (post hoc Tukey comparisons: $\mathrm{M}-\mathrm{H}: \quad p=0.0014, \mathrm{M}-\mathrm{P}: 0.6336, \mathrm{P}-\mathrm{H}$ : 0.0337).

\section{Discussion}

We demonstrate large TGEs of maternal sexual interactions spanning several generations. Both LRS and lifespan in offspring and grand-offspring were influenced by the maternal mating treatment imposed on F0 females. Remarkably, we did not find sizeable costs or benefits in the F0 generation to the mothers themselves. In C. maculatus, it has been previously shown that multiply-mated females live shorter than singly mated females (Crudgington and SivaJothy 2000; but see Fox 1993a; Arnqvist et al. 2004), which is thought to be caused, at least in part, by the sharp male genital spines that puncture the connective tissue within the female reproductive tract during mating (Dougherty et al. 2017; Dougherty and Simmons 2017; Rönn et al. 2007). Harassment of females by emasculated males (to remove potential effects associated with mating itself) has also been previously reported to lower reproductive success and longevity in this species (den Hollander and Gwynne 2009). High mating rates have, however, been shown to have beneficial effects on offspring production in this species (Arnqvist et al. 2004), potentially due to effects of large ejaculates on female hydration or nutritional status (Fox 1993a). Interestingly we find no costs of repeated mating or harassment on lifespan, and no effects of mating regimes on offspring production, in the maternal generation. However, our experiment reveals substantial effects of maternal mating treatment on subsequent generations. 
Fig. 3 Average lifespan and survival curves for male (virgin) and female (housed with mates for $24 \mathrm{~h}$ ) grand-offspring (F2).

Maternal treatment: Light grey: single mating (Mono, $\mathrm{M}$ ), grey: single mating + harassment $(\mathrm{H})$, dark grey: multiple mating with multiple males, Poly, P). a granddaughters average lifespan, b grandsons average lifespan; survival curves for granddaughters (c) and grandsons (d)
A Granddaughters Lifespan
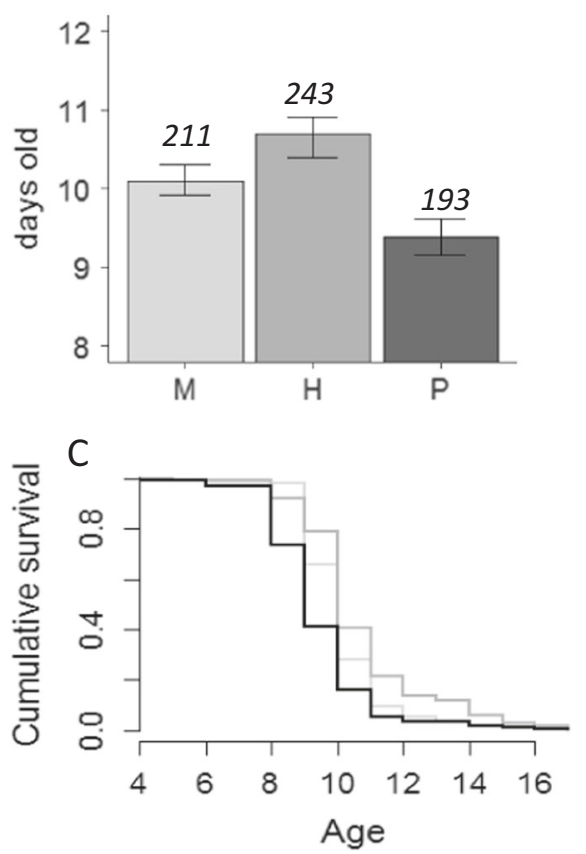

B Grandsons Lifespan

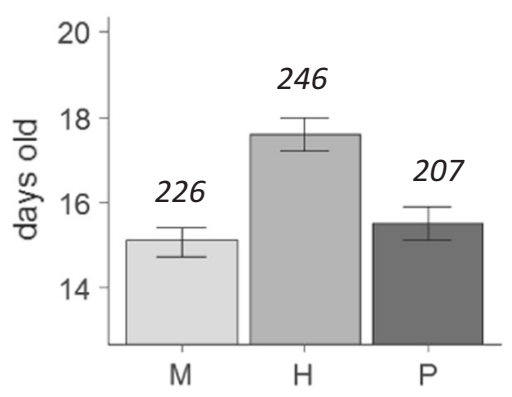

D

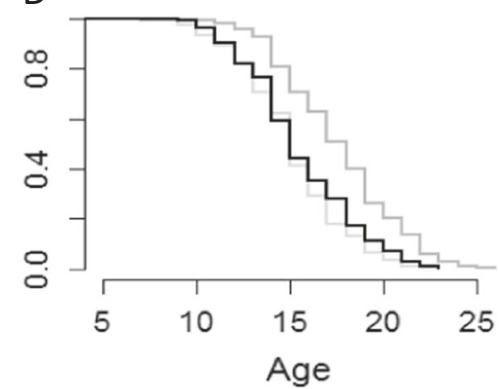

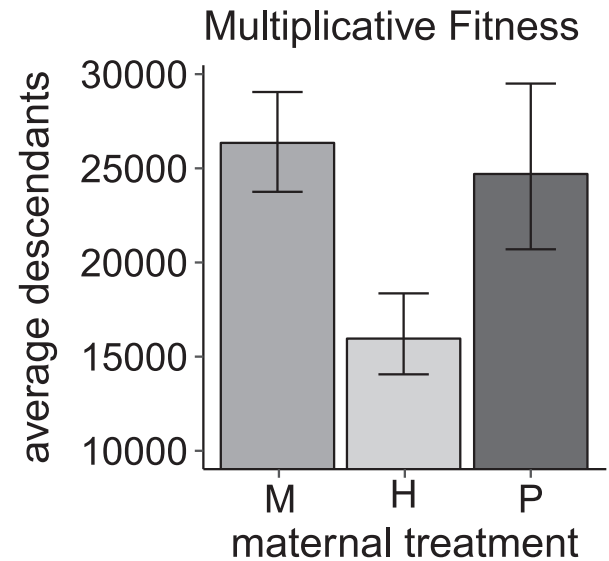

Fig. 4 Estimation for multiplicative fitness for females within the different mating treatments after three generations. Light grey: single mating (Mono, M), grey: single mating + harassment $(\mathrm{H})$, dark grey: multiple mating with multiple males, Poly, P)

The evaluation of fitness consequences beyond the parental generation is necessary if we want a comprehensive picture of the consequences of sexual interactions, and to understand the role of all effects, including the effects of the social environment, on the evolution of fitness-related traits. The importance of non-genetic inheritance has been highlighted in this special issue, and here we show that effects attributable to variation in levels of sexual interactions experienced by females in one generation can permeate across several generations, influencing reproductive success and survival patterns of future generations. While maternal effects arising from variations in social conditions have been studied extensively especially within the framework of maternal care (Champagne 2008), including their large role influencing offspring gene expression, only a few studies to date have investigated the role of transgenerational maternal sexual interactions. Recent studies in D. melanogaster found that daughters produce more offspring when their mothers had experienced higher levels of maternal sexual interactions (Garcia-Gonzalez and Dowling 2015; Priest et al. 2008a), whereas longevity and survival of offspring are negatively affected when produced by mothers that had experienced heightened sexual interactions (Dowling et al. 2014). Such TGEs have also been reported in guppies (Poecilia reticulata), whereby increased male presence and harassment led to lower reproductive success in offspring (Gasparini et al. 2012). Our results reflect this pattern found in guppies, because daughters from the harassment treatment had significantly lower levels of LRS than daughters from other treatment groups. However, this pattern was reversed in granddaughters, where descendants from harassed mothers had the highest LRS. Such a reversal of offspring fitness across different generations has also been found in a study in D. melanogaster, where sons were found to have increased fitness, but grandsons decreased fitness with increasing maternal sexual interactions (Brommer et al. 2012). In combination, these results highlight the importance of investigating the magnitude and direction of effects across multiple generations to understand the net transgenerational consequences of sexual interactions. Even in the absence of immediate costs and benefits due to sexual interactions potential reversing effects that occur in subsequent generations need to be taken into account to unveil 
the long-term consequences for the evolution of different mating strategies and mating systems.

While not as closely reflective of Darwinian fitness as the production of adult offspring over a lifetime, the TGEs we observed on survival are also noteworthy. Daughters from singly mated F0 females produced the largest numbers of offspring, and were found to have the shortest lifespan, reflecting a classic life-history trade-off. Similarly, this tradeoff was evident in $\mathrm{H}$ daughters, in the other direction, as this group displayed significantly longer survival but lowest reproductive outputs. Granddaughters from harassed F0 females (which had the highest levels of reproductive success), however, lived longest. The survival patterns were similar between the sexes, although male lifespan in the F1 sons was not influenced by their mothers mating treatment, in contrast to daughters. Grandsons from harassed F0 females lived significantly longer than those from singly or multiply mated F0 females, reflecting the pattern observed in granddaughters. This pattern of overall survival benefits to descendants from the harassment treatment is surprising, but highlights the importance of investigating TGEs across a variety of life-history traits, since they may reveal unexpected patterns of trait correlation both within and across generations. We did not find evidence for benefits of mating with multiple males, despite the fact that it has been shown in this species that the receipt of multiple ejaculates can confer direct benefits, in the form of additional hydration (Edvardsson 2007). It has been suggested that benefits of multiple mating may only be evident under nutrient-limited conditions (Fox 1993a), which may indicate that our environment was too benign to reveal differences. Lower levels of ambient humidity may be necessary to induce observable effects. However, it is also possible that the negative effects of harassment or harm in the multiply mated group masked the potential benefits that could be conferred directly to females. Negative effects of increasing copulations on female fecundity have been reported previously, while multiple mating conferred the overall benefit of increased fertilisation assurance (Wilson and Tomkins 2015), and has been associated with increasing egg size (Fox 1993b).

The TGEs in the grand-offspring generation alone indicate positive effects of grand-maternal harassment, both in lifespan and reproductive success. Taking overall fitness gains via female reproduction into account, however, our estimation of population growth via multiplicative fitness indicates that harassment overall bears very large negative fitness consequences, at least when measured across three generations. This indicates that TGEs and non-genetic inheritance of sexual interactions can have important impacts on the evolution of sexual interactions. While the interpretation of opposing patterns in different generations is complex, the strong effects observed in F1 indicate that IGEs, such as maternal effects, play an important role.
Specifically, harassment may induce low levels of fecundity in the offspring generation, for example via elevated stress levels in the F0 females. However, the increase in offspring numbers in the F2 generation may be due to an increase in offspring investment in the F1 mothers following very low levels of investment of the preceding generation. While we did not examine egg size, a possibility is that daughters from harassed mothers invested into fewer but larger eggs, which in turn could have developed into high performing offspring, both in terms of fecundity and longevity. Opposing patterns observed in the different generations may be caused by differences in how females allocate resources toward individual egg size relative to the number of eggs produced. Life history theory predicts that the number and size of offspring should trade-off (Smith and Fretwell 1974; Stearns 1989), and how females resolve this trade-off may vary depending on factors like female condition (Wilson et al. 2009), the phenotype of her mate (Kindsvater and Alonzo 2014; Qvarnström et al. 2000) or the conditions into which her offspring will be born (Fox and Czesak 2000; Parker and Begon 1986). The transgenerational fluctuations in LRS seen here for instance could result if harassed F0 females invest fewer resources in their eggs leading to the production of low condition daughters (F1), who then themselves go on to produce just a few high quality daughters (F2), who themselves go on to produce high numbers of offspring. Such plastic maternal effects are often linked to limited resources available to devote to offspring production, and are commonly observed across the animal kingdom (Brommer et al. 2012; Brown and Shine 2009; Lasne et al. 2017; Savalli and Fox 2002), including this study species (Fox 1993b; Fox et al. 1999, 1997). In particular, the role of fluctuating maternal effects in mediating the transgenerational fitness consequences of sexual interactions and sexual conflict is an avenue of research that deserves greater attention.

\section{Conclusion}

Our results indicate that harassment, when experienced without the apparent benefits of receiving ejaculates from multiple males, leads to suboptimal fitness consequences for daughters. However, different outcomes across generations indicate that it is necessary to include multiple generations when the net consequences of sexual interactions are being investigated. Sex-specific effects of maternal mating history on lifespan indicate the importance of investigating fitness traits in males and females separately. Our finding that costs and benefits may alternate between generations may indicate that socially mediated context-dependent effects may be important drivers of the evolutionary dynamics of sexual interactions. 


\section{Data archiving}

All data presented in this work can be accessed on Dryad. Provisional DOI: doi:10.5061/dryad.dp0fq30

Acknowledgements We thank three anonymous reviewers, Michael Sheriff and the editors of this special issue for comments on previous drafts, and Ryan Banks for help with the experiment. Funding was provided by a Talent Hub grant to SZ, the Australian Research Council for grants to DKD and MLH, and the Spanish Ministry of Economy for grants to FGG (CGL2012-34685 and CGL2016-76173-P, cofunded by the European Regional Development Fund)

\section{Compliance with ethical standards}

Conflict of interest The authors declare that they have no conflict of interest.

\section{References}

Arnqvist G, Nilsson T (2000) The evolution of polyandry: multiple mating and female fitness in insects. Anim Behav 60:145-164

Arnqvist G, Nilsson T, Katvala M (2004) Mating rate and fitness in female bean weevils. Behav Ecol 16. https://doi.org/10.1093/ beheco/arh119

Arnqvist G, Rowe L (2005) Sexual Conflict.. Princeton University Press, Princeton, New Jersey

Arnqvist R, Kirkpatrick M (2005) The evolution of infidelity in socially monogamous passerines: the strength of direct and indirect selection on extrapair copulation behavior in females. Am Nat 165:S26-S37

Bates D, Maechler M, Bolker B, Walker S (2015) Fitting linear mixedeffects models using lme4. J Stat Soft 67. https://doi.org/10. 18637/jss.v067.i01

Berg EC, Maklakov AA (2012) Sexes suffer from suboptimal lifespan because of genetic conflict in a seed beetle. Proc R Soc B 279 . https://doi.org/10.1098/rspb.2012.1345

Berger D, Berg EC, Widegren W, Arnqvist G, Maklakov AA (2014) Multivariate intralocus sexual conflict in seed beetles. Evol Int J Org Evol 68:3457-3469. https://doi.org/10.1111/evo.12528

Bilde T, Friberg U, Maklakov A, Fry J, Arnqvist G (2008) The genetic architecture of fitness in a seed beetle: assessing the potential for indirect genetic benefits of female choice. BMC Evol Biol 8:1-11. https://doi.org/10.1186/1471-2148-8-295

Blanckenhorn WU, Hosken DJ, Martin OY, Reim C, Teuschl Y, Ward PI (2002) The costs of copulating in the dung fly Sepsis cynipsea. Behav Ecol 353-358. https://doi.org/10.1093/beheco/13.3.353

Brommer JE, Fricke C, Edward DA, Chapman T (2012) Interactions between genotype and sexual conflict environment influence transgenerational fitness in Drosophila melanogaster. Evolution 66:517-531. https://doi.org/10.1111/j.1558-5646.2011.01449.x

Brown GP, Shine R (2009) Beyond size-number trade-offs: clutch size as a maternal effect. Philos Trans $\mathrm{R}$ Soc $\mathrm{B}$ Biol Sci 364:1097-1106. https://doi.org/10.1098/rstb.2008.0247

Cameron E, Day T, Rowe L (2003) Sexual conflict and indirect benefits. J Evol Biol 16:1055-1060

Champagne FA (2008) Epigenetic mechanisms and the transgenerational effects of maternal care. Front Neuroendocrinol, Spec Issue: Epigenetics 29:386-397. https://doi.org/10.1016/j.yfrne. 2008.03.003

Chapman T, Arnqvist G, Bangham J, Rowe L (2003) Sexual conflict. Trends Ecol Evol 18:41-47
Chapman T, Liddle LF, Kalb JM, Wolfner MF, Partridge L (1995) Cost of mating in Drosophila melanogaster females is mediated by male accessory gland products. Nature 373:241-244. https:// doi.org/10.1038/373241a0

Chippindale AK, Gibson JR, Rice WR (2001) Negative genetic correlation for adult fitness between sexes reveals ontogenetic conflict in Drosophila. Proc Natl Acad Sci USA 98. https://doi.org/ 10.1073/pnas.041378098

Credland PF, Wright AW (1989) Factors affecting female fecundity in the cowpea seed beetle, Callosobruchus maculatus (Coleoptera: Bruchidae). J Stored Prod Res 25:125-136. https://doi.org/10. 1016/0022-474X(89)90034-9

Crudgington HS, Siva-Jothy MT (2000) Genital damage, kicking and early death. Nature 407:855-856. https://doi.org/10.1038/ 35038154

den Hollander M, Gwynne DT (2009) Female fitness consequences of male harassment and copulation in seed beetles. Callosobruchus maculatus Anim Behav 78:1061-1070. https://doi.org/10.1016/j. anbehav.2009.06.036

Dougherty LR, Lieshout E, van, McNamara KB, Moschilla JA, Arnqvist G, Simmons LW (2017) Sexual conflict and correlated evolution between male persistence and female resistance traits in the seed beetle Callosobruchus maculatus. Proc R Soc B 284:20170132. https://doi.org/10.1098/rspb.2017.0132

Dougherty LR, Simmons LW (2017) X-ray micro-CT scanning reveals temporal separation of male harm and female kicking during traumatic mating in seed beetles. Proc R Soc B 284:20170550. https://doi.org/10.1098/rspb.2017.0550

Dowling DK, Williams BR, Garcia-Gonzalez F (2014) Maternal sexual interactions affect offspring survival and ageing. J Evol Biol 27:88-97. https://doi.org/10.1111/jeb.12276

Eady PE, Rugman-Jones P, Brown DV (2004) Prior oviposition, female receptivity and last-male sperm precedence in the cosmopolitan pest Callosobruchus maculatus (Coleoptera: Bruchidae). Anim Behav 67:559-565. https://doi.org/10.1016/j.anbeha v.2003.07.003

Edvardsson M (2007) Female Callosobruchus maculatus mate when they are thirsty: resource-rich ejaculates as mating effort in a beetle. Anim Behav 74:183-188. https://doi.org/10.1016/j.anbeha v.2006.07.018

Fedorka KM, Mousseau TA (2004) Female mating bias results in conflicting sex-specific offspring fitness. Nature 429:65-67. https://doi.org/10.1038/nature02492

Foerster K, Coulson T, Sheldon BC, Pemberton JM, Clutton-Brock TH, Kruuk LEB (2007) Sexually antagonistic genetic variation for fitness in red deer. Nature 447. https://doi.org/10.1038/na ture 05912

Fox CW (1993a) Multiple mating, lifetime fecundity and female mortality of the bruchid beetle, Callosobruchus maculatus (Coleoptera: Bruchidae). Funct Ecol 7. https://doi.org/10.2307/ 2389888

Fox CW (1993b) The influence of maternal age and mating frequency on egg size and offspring performance in Callosobruchus maculatus (Coleoptera: Bruchidae). Oecologia 96:139-146. https://doi.org/10.1007/BF00318042

Fox CW, Bush ML, Wallin WG (2003) Maternal age affects offspring lifespan of the seed beetle. Callosobruchus maculatus Funct Ecol 17:811-820. https://doi.org/10.1111/j.1365-2435.2003.00799.x

Fox CW, Czesak ME (2000) Evolutionary ecology of progeny size in arthropods. Annu Rev Entomol 45:341-369. https://doi.org/10. 1146/annurev.ento.45.1.341

Fox CW, Czesak ME, Mousseau TA, Roff DA (1999) The evolutionary genetics of an adaptive maternal effect: egg size plasticity in a seed beetle. Evolution 53:552-560. https://doi.org/10.1111/j. 1558-5646.1999.tb03790.x 
Fox CW, Thakar MS, Mousseau TA (1997) Egg size plasticity in a seed beetle: an adaptive maternal effect. Am Nat 149:149-163

Garcia-Gonzalez F, Dowling DK (2015) Transgenerational effects of sexual interactions and sexual conflict: non-sires boost the fecundity of females in the following generation. Biol Lett 11:20150067. https://doi.org/10.1098/rsbl.2015.0067

Garcia-Gonzalez F, Simmons LW (2010) Male-induced costs of mating for females compensated by offspring viability benefits in an insect. J Evol Biol 23:2066-2075. https://doi.org/10.1111/j. 1420-9101.2010.02065.x

García-González F, Simmons LW (2007) Paternal indirect genetic effects on offspring viability and the benefits of polyandry. Curr Biol 17:32-36. https://doi.org/10.1016/j.cub.2006.10.054

Gasparini C, Devigili A, Pilastro A (2012) Cross-generational effects of sexual harassment on female fitness in the guppy. Evolution 66:532-543. https://doi.org/10.1111/j.1558-5646.2011.01455.x

Gavrilets S, Arnqvist G, Friberg U (2001) The evolution of female mate choice by sexual conflict. Proc Biol Sci 268:531-539. https://doi.org/10.1098/rspb.2000.1382

Head ML, Hunt J, Jennions MD, Brooks R (2005) The indirect benefits of mating with attractive males outweigh the direct costs. PLoS Biol 3. https://doi.org/10.1371/journal.pbio.0030033

Holland B, Rice WR (1998) Chase-away selection: antagonistic seduction versus resistance. Evolution 52:1-7

Hothorn T, Bretz F, Westfall P (2008) Simultaneous inference in general parametric models. Biometrical J 50:346-363

Jennions MD, Petrie M (2000) Why do females mate multiply? A review of the genetic benefits. Biol Rev Camb Philos Soc $75: 21-64$

Kindsvater HK, Alonzo SH (2014) Females allocate differentially to offspring size and number in response to male effects on female and offspring fitness. Proc R Soc B Biol Sci 281. https://doi.org/ 10.1098/rspb.2013.1981

Kokko H, Brooks R, Jennions MD, Morley J (2003) The evolution of mate choice and mating biases. Proc R Soc LondonSeries B-Biol Sci 270, 653-664

Kuznetsova A, Brockhoff PB, Christensen RHB (2013) lmerTest: Tests for random and fixed effects for linear mixed effect models (lmer objects oflme4 package). R Package Version2

Lasne E, Leblanc CA-L, Gillet C (2017 Egg size versus number of offspring trade-off: female age rather than size matters in a domesticated arctic charr population. Evol Biol 1-8. https://doi. org/10.1007/s11692-017-9433-8

Le Galliard JF, Cote J, Fitze PS (2008) Lifetime and intergenerational fitness consequences of harmful male interactions for female lizards. Ecology 89:56-64. https://doi.org/10.1890/06-2076.1

Messina FJ (1991) Life-history variation in a seed beetle: adult egglaying vs. larval competitive ability. Oecologia 85:447-455

Orteiza N, Linder JE, Rice WR (2005) Sexy sons from re-mating do not recoup the direct costs of harmful male interactions in the Drosophila melanogaster laboratory model system. J Evol Biol 18:1315-1323. https://doi.org/10.1111/j.1420-9101.2005.00923.x

Parker GA (2006) Sexual conflict over mating and fertilization: an overview. Philos Trans R Soc Lond B Biol Sci 361:235-259. https://doi.org/10.1098/rstb.2005.1785

Parker GA, Begon M (1986) Optimal egg size and clutch size: effects of environment and maternal phenotype. Am Nat 128:573-592. https://doi.org/10.1086/284589

Partridge L, Fowler K (1990) Non-mating costs of exposure to males in female Drosophila melanogaster. J Insect Physiol 36:419-425
Pischedda A, Chippindale AK (2006) Intralocus sexual conflict diminishes the benefits of sexual selection. PLoS Biol 4. https:// doi.org/10.1371/journal.pbio.0040356

Priest NK, Galloway LF, Roach DA (2008a) Mating frequency and inclusive fitness in Drosophila melanogaster. Am Nat 171:10-21. https://doi.org/10.1086/523944

Priest NK, Roach DA, Galloway LF (2008b) Cross-generational fitness benefits of mating and male seminal fluid. Biol Lett 4:6-8. https://doi.org/10.1098/rsbl.2007.0473

Qvarnström A, Pärt T, Sheldon BC (2000) Adaptive plasticity in mate preference linked to differences in reproductive effort. Nature 405:344-347. https://doi.org/10.1038/35012605

R Development Core Team (2012) R: A language and environment for statistical computing. R Foundation for Statistical Computing, Vienna, Austria

Reece SE, Wherry RN, Bloor JMG (2005) Sex allocation and interactions between relatives in the bean beetle. Callosobruchus maculatus Behav Process 70:282-288. https://doi.org/10.1016/j. beproc.2005.08.002

Reznick D (1985) Costs of reproduction: an evaluation of the empirical evidence. Oikos 44:257-267. https://doi.org/10.2307/ 3544698

Rönn J, Katvala M, Arnqvist G (2007) Coevolution between harmful male genitalia and female resistance in seed beetles. Proc Natl Acad Sci USA 104:10921-10925. https://doi.org/10.1073/pnas. 0701170104

Rundle HD, Ödeen A, Mooers AØ (2007) An experimental test for indirect benefits in Drosophila melanogaster. BMC Evol Biol 7:36. https://doi.org/10.1186/1471-2148-7-36

Savalli UM, Fox CW (2002) Proximate mechanisms influencing egg size plasticity in the seed beetle Stator limbatus (Coleoptera: Bruchidae). Ann Entomol Soc Am 95:724-734. https://doi.org/ 10.1603/0013-8746(2002)095[0724:PMIESP]2.0.CO;2

Smith CC, Fretwell SD (1974) The optimal balance between size and number of offspring. Am Nat 108:499-506. https://doi.org/10. $1086 / 282929$

Stearns SC (1989) Trade-offs in life-history evolution. Funct Ecol 3:259-268. https://doi.org/10.2307/2389364

Stewart AD, Hannes AM, Mirzatuny A, Rice WR (2008) Sexual conflict is not counterbalanced by good genes in the laboratory Drosophila melanogaster model system. J Evol Biol 21:1808-1813. https://doi.org/10.1111/j.1420-9101.2008.01593.x

Stewart AD, Morrow EH, Rice WR (2005) Assessing putative interlocus sexual conflict in Drosophila melanogaster using experimental evolution. Proc R Soc B Biol Sci 272:2029-2035. https:// doi.org/10.1098/rspb.2005.3182

Therneau TM (2015) Coxme: Mixed Effects Cox Models. http:// CRAN.R-project.org $/$ package $=$ coxme

Williams GC (1966) Natural selection, the costs of reproduction, and a refinement of Lack's principle. Am Nat 100:687-690

Wilson AJ, Pemberton JM, Pilkington JG, Clutton-Brock TH, Kruuk LEB (2009) Trading offspring size for number in a variable environment: selection on reproductive investment in female Soay sheep. J Anim Ecol 78:354-364. https://doi.org/10.1111/j. 1365-2656.2008.01489.x

Wilson CJ, Tomkins JL (2015) Female Callosobruchus maculatus can maximize long-term fitness through polyandry. Behav Ecol 26:502-509. https://doi.org/10.1093/beheco/aru218 